
\title{
25 Research Suare \\ Polymorphism in the progesterone receptor promoter gene in endometrial cancer alters its expression
}

\section{Zhengwu Xiao}

Hunan Provincial Key Laboratory of tumor microenvironment responsive drug research

Huahua Xiang

Hunan Provincial Key Laboratory of tumor microenvironment responsive drug research

Jing Zhou

Hunan Provincial Key Laboratory of tumor microenvironment responsive drug research

Chen Zhou

Hunan Provincial Key Laboratory of tumor microenvironment responsive drug research

Zifen Guo ( $\square$ guozifen@aliyun.com )

Hunan Provincial Key Laboratory of tumor microenvironment responsive drug research

\section{Research}

Keywords: Endometrial cancer; Progesterone receptor gene polymorphism; Western Blot; Real-time PCR;

Clinical pathological features.

Posted Date: February 20th, 2020

DOl: https://doi.org/10.21203/rs.2.24112/v1

License: (c) (i) This work is licensed under a Creative Commons Attribution 4.0 International License.

Read Full License 


\section{Abstract}

The purpose of this study was to investigate the effect of progesterone receptor (PGR) promoter $+331 \mathrm{G} / \mathrm{A}$ polymorphism on the mRNA and protein expression of its two isoforms, PRA and PRB, in healthy control women and women with endometrial cancer. To evaluate the relative occurrence of $+331 \mathrm{G} / \mathrm{A}$ polymorphism, the PGR gene promoter in the whole blood of 66 healthy volunteers and 62 endometrial cancer patients was genotyped. The results demonstrate that the frequency of GG and the overall frequency of the $\mathrm{G}$ allele were $>90 \%$ in both populations. The GA+AA genotypes were more common in the healthy control group than in the endometrial cancer group, though the differences were not statistically significant. RT-PCR and Western blot analysis results showed that the mRNA and protein levels of both PRB and PRA were significantly lower in endometrium from cancer patients than in normal endometrium tissue. Furthermore, among individuals with endometrial cancer, those with the $+331 \mathrm{G} / \mathrm{A}$ polymorphism expressed higher mRNA levels of the PRA isoform and higher protein levels of the PRB isoform. Therefore, our findings suggest that patients with endometrial cancer express less PGR and that the mRNA and protein expression of PRA and PRB may be altered due to 331G/A PGR gene polymorphism.

\section{Introduction}

Endometrial cancer $(\mathrm{EC})$ is one of the most common gynecologic malignancies. With the increase in morbidity and the postponement of women's reproductive age, the proportion of women with endometrial cancer who have not yet given birth has gradually increased[1, 2]. Studies have shown that the occurrence of endometrial cancer is associated with long-term absence of estrogen stimulation and progesterone antagonism. For estrogen-dependent tumors, the sooner the cancer is detected, the better the prognosis. Since 1951, when Kelly suggested that progesterone inhibits the growth of endometrial cancer cells, a large amount of data has been reported supporting this function of progesterone, and its effect on endometrial cancer has been recognized[3].

The physiologic effects of progesterone are mediated via its receptor, which is a member of the steroid receptor super-family of nuclear receptors. The human progesterone receptor (PGR) is transcribed by two alternative promoters that direct its translation into two isoforms, progesterone receptor $A(P R A)$ and progesterone receptor $B(P R B)[4,5]$. These two isoforms mediate all major responses to progesterone. Their expression levels in most normal progesterone target cells are similar, and the PRA/PRB balance regulates the expression of many other genes and the physiological response to progesterone, with potentially serious consequences attributed to their dysregulation. Furthermore, PGR polymorphisms may break the balance between PRA and PRB, which may, in turn, affect the therapeutic effect of progesterone on endometrial cancer. Therefore, we speculate that PGR polymorphism may influence the occurrence, development and treatment of endometrial cancer by affecting the ratio of PRA and PRB[6, 7].

The human PGR gene has eight exons and seven introns and is located in chromosome 11q22-23. The PGR +331 locus is located between the transcription start site of PRB (+1) and PRA (+ 751). Guanine can 
be replaced by adenine, resulting in 3 genotypes: homozygous GG, AA and heterozygous GA. Notably, + $331 \mathrm{G}$ to A single nucleotide polymorphism (SNP) produces a TATA - box. Because the PGR promoter region lacks a TATA-box structure, the new TATA-box generates a de novo transcriptional start site and increases the transcriptional activity of PGR[8-10]. However, the effects of this mutation are controversial. In a controlled study of 187 cases of endometrial cancer and 397 healthy controls, De Vivo[11] found that the $+331 \mathrm{G}$ to A polymorphism is associated with increased risk of endometrial cancer. In contrast, Dossus[12] did not find an association of $+331 \mathrm{G} / \mathrm{A}$ with risk, but determined that endometrial cancer patients were older $(P=0.001)$ and had a higher body mass index $(P=0.004)$ than the controls, with $9 \%$ of the case group and only $6 \%$ of the control group being premenopausal. Since progesterone treatment for endometrial cancer mainly works through PRB, we speculated that the change from $+331 \mathrm{G}$ to $A$ might enhance the efficacy of progesterone by increasing the PRB/PRA ratio.

To further evaluate the correlation of PRB and PRA expression with the occurrence and development of endometrial cancer, as well as its therapeutic effect, we established a detection platform for molecular switch technology, with the purpose of rapidly and effectively classifying PGR gene + 331G/A SNPs in blood collected from healthy controls and patients with endometrial cancer and the effects on PRA/PRB mRNA and protein expression. Our results provide a foundation for further elucidating the correlation between progesterone receptor gene polymorphism and endometrial cancer in order to guide the implementation of individualized drug use in progesterone treatment.

\section{Materials And Methods}

\section{Sample collection}

Blood samples were collected from 66 healthy women in the Second Affiliated Hospital of the University of South China from October 2014 to August 2015, and from 62 patients with endometrial cancer admitted to the First Affiliated Hospital of the University of South China between May 2015 and July 2017 (Fig. 1 and Table 1). Additionally, tissue samples from the 62 cases of endometrial cancer patients and 12 healthy women were collected. The patients had not received radiotherapy, chemotherapy, or hormone therapy before examination or surgery, nor had they been diagnosed with other diseases, such as heart disease, hypertension, diabetes, or malignant tumors. Postoperative diagnosis was made through pathological tissue sections (Fig. 2).

\section{Single-nucleotide polymorphism detection}

Normal blood DNA was extracted as template, and site-directed mutation primers at the $+331 \mathrm{G} / \mathrm{A}$ site were designed. Based on the site-directed mutation principle of overlapping PCR, PGR gene fusion fragments containing the wild-type $+331 \mathrm{G}$ or mutant $+331 \mathrm{~A}$ sequence were obtained and verified by DNA sequencing. Wild-type and mutant detection primers at the $+331 \mathrm{G} / \mathrm{A}$ site were designed using the constructed recombinant gene fragments as template and were sulfide modified at the 3 terminal (Table 2). Genotyping of PGR $+331 \mathrm{G} / \mathrm{A}$ polymorphisms in DNA extracted from the whole blood and endometrial tissues of healthy controls and endometrial cancer patients was conducted by PCR as 
follows: initial denaturing, $95^{\circ} \mathrm{C}$ for 3 minutes; 30 cycles of repeated denaturing at $95^{\circ} \mathrm{C}$ for 30 seconds, annealing at $56^{\circ} \mathrm{C}$ for 30 seconds, and extension at $72{ }^{\circ} \mathrm{C}$ for 30 seconds; and final extension at $72{ }^{\circ} \mathrm{C}$ for 4 minutes. PCR products were resolved on 1.5\% agarose gels, and DNA bands were visualized by ethidium bromide staining.

\section{RNA isolation, reverse transcription and real-time PCR}

Total RNA from endometrial cancer and normal tissue was isolated using a RNA extraction Kit (CW0597S). Total RNA $(2 \mu \mathrm{g})$ from each sample was reverse-transcribed using the FastKing one-step genomic cDNA first strand synthesis premixed reagent (KR118). Primers targeting PGA, PRB or GAPDH genes (Table 3) have been described previously. PCR was performed using SYBR Green Master Mix (TIANGEN) with the CFX96 TouchTM Real Time PCR System. PCR conditions were as follows: initial denaturing, $95^{\circ} \mathrm{C}$ for 15 minutes; 40 cycles of repeated denaturing at $95^{\circ} \mathrm{C}$ for 10 seconds, annealing at $60{ }^{\circ} \mathrm{C}$ for 20 seconds, and extension at $72{ }^{\circ} \mathrm{C}$ for 20 seconds; and then final extension at $72{ }^{\circ} \mathrm{C}$ for 4 minutes. As negative control, a "water only" sample was included in the reverse transcription step to rule out genomic DNA contamination. Quantification was performed only if the dissociation curve was specific. The target genes were quantitatively evaluated by the method of $\Delta \Delta \mathrm{Ct}$. Levels of PRA were obtained by subtracting the PRB expression value from the PGR expression value. All assays were performed in triplicate.

\section{Western Blotting of endometrial samples}

Tissue sample were cut into pieces and lysed in RIPA buffer at a ratio of 150-250 $\mu \mathrm{L}$ per $20 \mathrm{mg}$ of tissue. The samples were agitated on ice to ensure complete lysis, and then centrifuged for 15-30 minutes at $12,000 \mathrm{rpm}$ at $4{ }^{\circ} \mathrm{C}$ to remove the pellet. Protein concentrations were determined by BCA assay. Total extracted protein was mixed with 5×SDS-PAGE loading Buffer at a 4:1 ratio, heated 5-10 minutes at $95{ }^{\circ} \mathrm{C}$, separated on a $10 \%$ SDS-polyacrylamide gel, and electroblotted onto polyvinylidence difluoride membranes. The membranes were blocked with $5 \%$ nonfat dry milk in 1xTBST for 2 hours at room temperature and then incubated with anti-PR antibody (diluted 1:1000 with Western Antibody Dilution Buffer) at $4^{\circ} \mathrm{C}$ overnight or for $2-4$ hours at room temperature. After 3 washes, the membranes were incubated for 45 minutes with secondary antibody (diluted 1:8000-1:10000). Detection was achieved by enhanced chemiluminescence. Antibodies against PRA, PRB, and $\beta$-actin were obtained from Absin (Shanghai, China). All assays were performed in triplicate.

\section{Statistical analysis}

All data groups were analyzed by SPSS 18.0 to determine if there were significant differences among the data. Genotype frequency and gene frequency were calculated by the direct counting method, and the data were compared by the Student's $t$ test or the $x^{2}$ test.

\section{Results}

\section{Assessment of $+331 \mathrm{G} / \mathrm{A}$ SNP $\mathrm{s}$ in endometrial cancer}


The whole blood DNA of 66 healthy controls and 62 cases of endometrial carcinoma was genotyped with the assistance of a high-fidelity DNA enzyme (Fig. 3). The results demonstrate that the genotype distribution frequency of $+331 \mathrm{G} / \mathrm{A}$ in the endometrial cancer patients group (GG, 93.55\% and GA+AA, $6.45 \%$ ) was not statistically different from the distribution in the healthy control group (GG, $90.91 \%$ and GA+AA, 9.09\%) (Fig. 4A). The overall frequency of the $G$ allele was lower in the endometrial cancer group (94.70\%) than in the healthy control group (95.97\%), while the overall frequency of the A allele was higher in the endometrial cancer group (5.30\%) than the healthy control group (4.30\%), though the difference was not statistical (Fig.4B)(Table 4). These results suggest that the $+331 \mathrm{G} / \mathrm{A}$ allele frequency for healthy controls and patients with endometrial cancer in the population that we evaluated was similar.

\section{Evaluation of PRA and PRB mRNA expression in cancerous and normal samples by RT-PCR}

To further examine potential differences in PRA and PRB allele expression, we performed RT-PCR of tissues from 62 patients with endometrial carcinoma and 12 patients with normal endometrium. The results show that mRNA levels of PRB, total PGR and PRA were significantly lower in endometrial cancer patients' tissue as compared to the healthy control group $(0.396,0.306,0.237)(P<0.05)$, though the PRA/PRB ratio was not statistically different for the two groups ( $P>0.05)$ (Fig. 5 and Table 5). These results suggest that endometrial cancer patients express less PGR mRNA, but that differences in the PRA/PRB ratio are not obvious.

\section{Correlation between PRA mRNA expression and +331G/A polymorphism}

To determine whether there is a correlation between $+331 \mathrm{G} / \mathrm{A}$ polymorphism and PGR expression among the patients with endometrial cancer, we compared the mRNA expression levels for tissue sample DNA of 58 patients in the case group that had either GG or GA+AA alleles. As a positive control for PRG expression, 12 samples from the healthy control group that had GG alleles were assayed in parallel. Consistent with the results from Fig. 5, the overall expression of PGR, PRA and PRB was reduced in patients with endometrial cancer as compared to the healthy controls (Fig.6 and Table 6). Furthermore, there were no statistical differences in the relative expression level of PRB and total PGR mRNA for the $G A+A A$ group as compared to the $G G$ group of patients with endometrial cancer $(P>0.05)$. On the other hand, the relative expression levels of PRA mRNA and the PRA/PRB ratio were statistically higher in the $G A+A A$ group than in the $G G$ group $(P<0.05)$. These results suggest that individuals with endometrial cancer who carry the $+331 \mathrm{G} / \mathrm{A}$ polymorphism preferentially express the PRA isoform.

\section{Correlation between PRB protein expression and +331G/A polymorphism}


To determine whether this trend could be observed at the protein level, we performed Western blotting. The levels of PRA and PRB in both the GG group and GA+AA group of patients with endometrial cancer were significantly lower than those in the control group (Fig. 7; $P<0.05$ ), which is consistent with our PCR results. However, the level of PRB was lower in the GG group than in the GA+AA group, with a statistically significant difference $(P<0.05)$, while the PRA/PRB ratio was significantly higher for the GG group than for the $G A+A A$ group $(P<0.05)$. This is opposite of the results observed at the RNA level and suggests that relative protein expression levels may be determined by post-translational effects rather than transcriptional mechanisms.

\section{Discussion}

Endometrial cancer accounts for about $7 \%$ of all malignant tumors and $20-30 \%$ of female reproductive tract malignant tumors. The incidence of endometrial cancer has surpassed the incidence of cervical cancer, the morbidity tends to affect younger women, and the survival rate has also become significantly reduced[13]. The 2018 NCCN clinical practice guidelines for uterine tumors indicates that treatment of endometrial cancer with systemic chemotherapy and hormone therapy is ineffective and requires surgical treatment, which is mainly used for recurrence, metastasis or high-risk patients. For patients who want to maintain reproductive function, treatment with megestrol, medroxyprogesterone acetate and the levonorgestrel intrauterine sustained-release system can be used, and PGR positivity has become one of the important determinants of efficacy.

Based on mutation sensitivity molecular switch technology, deafness gene mutations and SNP sites for breast cancer gene mutations have been efficiently and rapidly detected[14, 15]. Therefore, we conducted molecular switch technology to evaluate PGR expression in patients with endometrial cancer in conjunction with $+331 \mathrm{G} / \mathrm{A}$ site genotyping and detection of mRNA and protein levels of PRA and PRB. In our study, the SNP-sensitive molecular switch technique was applied using optimal reaction conditions to genotype PGR +331 G/A polymorphism in the whole blood DNA of 66 healthy controls and 62 endometrial cancer patients. We determined that the genotype distribution frequency of $+331 \mathrm{G} / \mathrm{A}$ in patients with endometrial cancer was GG (93.55\%) and GA + AA (6.45\%), and the difference was not statistically significant $(P>0.05)$ compared with GG $(90.91 \%)$ and GA $+\mathrm{AA}(9.09 \%)$ in the healthy control group. The frequency of the $\mathrm{G}$ allele in the endometrial cancer patient group and the control group was $94.70 \%$ and $95.97 \%$, respectively, and the frequency of the A allele in the two groups was $5.30 \%$ and $4.03 \%$, respectively. The distribution difference of the allele frequency between the two groups was not statistically significant $(P>0.05)$, though the frequency of $A$ alleles was far less than that of $G$ alleles, which is consistent with the reports in the NCBI database.

To further evaluate the effect of PGR gene $+331 \mathrm{G} / \mathrm{A}$ polymorphism, we assessed the mRNA and protein expression of PRA and PRB in endometrial patients of differing genotypes. The result showed that the mRNA expression of PRB, PGR and PRA in the cancerous tissues of patients with endometrial cancer was reduced $(P<0.05)$, suggesting that the occurrence of endometrial cancer is associated with decreased expression of PGR, regardless of the isoform that is expressed. Furthermore, statistical analysis showed 
that PRA mRNA and the PRA/PRB ratio were higher in the GA+AA group than in the GG group $(P<0.05)$, suggesting that the presence of $+331 \mathrm{~A}$ may increase the expression of the PRA isoform. The latter result is inconsistent with other published studies (refs) and needs to be validated with a larger sample size.

We also used Western blot analysis to detect the expression levels of PRA and PRB protein in the endometrial tissue samples of each group. The results confirm that the levels of PRA and PRB were significantly reduced in the tissues of patients with endometrial carcinoma in both the GG group and GA+AA group compared with the healthy control group $(P<0.05)$. Additionally, the levels of PRB in the GA+AA group were significantly increased compared with those in the GG group $(P<0.05)$. Given that this difference was not detected at the mRNA level, it is possible that PGR expression is regulated by posttranslational mechanisms such as differences in degradation or secretion rates. Additional analyses in the future may reveal the mechanisms that regulate PGR isoform expression at the mRNA and protein levels. Nevertheless, our observations that the expression of PRA and PRB mRNA and protein are elevated in endometrial cancer is consistent with the idea that increased PGR expression may promote the development of endometrial carcinoma.

In conclusion, the SNP molecular switch method can be used for DNA gene analysis in patients with endometrial carcinoma tissue. This method not only has the characteristics of simple operation, rapidity and accuracy, but also may have value in clinical research related to genetic testing for cancer diagnosis, treatment and medicine. The mRNA and protein levels of PGR, PRA, and PRB were significantly reduced in cancer tissues $(P<0.05)$. Therefore, we speculate that the transcription and expression of PGR and its isoforms play an important role in the development and progression of endometrial cancer. Future studies may reveal whether polymorphism of $+331 \mathrm{G} / \mathrm{A}$ may affect the development and progression of endometrial cancer. Thus, gene polymorphism testing provides a preclinical research foundation and potentially a basis for clinical application of drug sensitivity.

\section{Declarations}

\section{Competing interests}

The authors declare that they have no competing interests.

\section{Funding}

This study is partially supported by the Hunan Provincial Natural Science Foundation of China (grant no. 2018JJ2350) and the Key project of Education Department of Hunan Province(grant no. 19A419)

\section{Author Contribution}

ZWX: protocol development,sample and data collection, data analysis, manuscript writing. HHX: protocol development, protocol development data collection, manuscript proofreading. JZ: sample and data collection, manuscript proofreading. CZ: review of literature, Manuscript proofreading. ZFG: review of literature, manuscript proofreading, and editing. 


\section{Ethical approval}

All procedures performed in studies involving human participants were in accordance with the ethical standards of the institutional and/or national research committee and with the 1964 Helsinki declaration and its later amendments or comparable ethical standards.

\section{Acknowledgements}

First and foremost, I would like to show my deepest gratitude to my supervisor, Prof. Guo Zifen, a respectable, responsible and resourceful scholar, who has provided me with valuable guidance in every stage of the writing of this thesis. Without her enlightening instruction, impressive kindness and patience, I

could not have completed my thesis. her keen and vigorous academic observation enlightens me not only in this thesis but also in my future study. I shall extend my thanks to Mrs. Xiang for all her kindness and help. I would also like to thank all my teachers who have helped me to develop the fundamental and essential academic competence. My sincere appreciation also goes to the teachers and students from University of South China, who participated this study with great cooperation. Last but not least, l' d like to thank all my friends, especially my girlfriend, for her encouragement and support.

\section{Consent for publication}

Written informed consent for publication was obtained from all participants.

\section{Availability of data and material}

All data generated or analysed during this study are included in this published article

\section{References}

1. Casey MJ, Crotzer D (2019) Cancer, Endometrial. In: StatPearls. StatPearls Publishing StatPearls Publishing LLC., Treasure Island (FL),

2. Siegel RL, Miller KD, Jemal A (2018) Cancer statistics, 2018. CA: a cancer journal for clinicians 68 (1):7-30. doi:10.3322/caac.21442

3. McMeekin DS, Gordon A, Fowler J, Melemed A, Buller R, Burke T, Bloss J, Sabbatini P (2003) A phase II trial of arzoxifene, a selective estrogen response modulator, in patients with recurrent or advanced endometrial cancer. Gynecologic oncology 90 (1):64-69

4. Smith D, Stewart CJR, Clarke EM, Lose F, Davies C, Armes J, Obermair A, Brennan D, Webb PM, Nagle CM, Spurdle AB (2018) ER and PR expression and survival after endometrial cancer. Gynecologic oncology 148 (2):258-266. doi:10.1016/j.ygyno.2017.11.027

5. Petousis S, Prapas Y, Margioula-Siarkou C, Ravanos K, Milias S, Mavromatidis G, Kalogiannidis I, Haitoglou C, Athanasiadis A, Prapas N, Rousso D (2018) Unexplained infertility patients present the 
mostly impaired levels of progesterone receptors: Prospective observational study. American journal of reproductive immunology (New York, NY : 1989) 79 (6):e12828. doi:10.1111/aji.12828

6. Renner SP, Strick R, Fasching PA, Oeser S, Oppelt P, Mueller A, Beckmann MW, Strissel PL (2008) Single nucleotide polymorphisms in the progesterone receptor gene and association with uterine leiomyoma tumor characteristics and disease risk. American journal of obstetrics and gynecology 199 (6):648.e641-649. doi:10.1016/j.ajog.2008.06.015

7. Romano A, Delvoux B, Fischer DC, Groothuis P (2007) The PROGINS polymorphism of the human progesterone receptor diminishes the response to progesterone. Journal of molecular endocrinology 38 (1-2):331-350. doi:10.1677/jme.1.02170

8. Veronica M, Ali A, Venkateshwari A, Mamata D, Nallari P (2016) Association of estrogen and progesterone receptor gene polymorphisms and their respective hormones in uterine leiomyomas. Tumour biology : the journal of the International Society for Oncodevelopmental Biology and Medicine 37 (6):8067-8074. doi:10.1007/s13277-015-4711-5

9. De Vivo I, Huggins GS, Hankinson SE, Lescault PJ, Boezen M, Colditz GA, Hunter DJ (2002) A functional polymorphism in the promoter of the progesterone receptor gene associated with endometrial cancer risk. Proceedings of the National Academy of Sciences of the United States of America 99 (19):12263-12268. doi:10.1073/pnas.192172299

10. Pabalan N, Pineda MR, Jarjanazi H, Christofolini DM, Barbosa CP, Bianco B (2015) Association of the $+331 \mathrm{G} / \mathrm{A}$ progesterone receptor gene $(\mathrm{PgR})$ polymorphism with risk of endometrial cancer in Caucasian women: a meta-analysis. Archives of gynecology and obstetrics 291 (1):115-122. doi:10.1007/s00404-014-3344-z

11. Terry KL, De Vivo I, Titus-Ernstoff L, et al. Genetic variation in the progesterone receptor gene and ovarian cancer risk[J]. American journal of epidemiology, 2005,161 (5):442-451.

12. Liao J, Ding D, Sun C, et al. Polymorphisms of progesterone receptor and ovarian cancer risk: a systemic review and meta-analysis[J]. The journal of obstetrics and gynaecology research, 2015,41(2):178-187.

13. Britton H, Huang L, Lum A, Leung S, Shum K, Kale M, Burleigh A, Senz J, Yang W, McConechy M, Kommoss S, Brucker S, Talhouk A, Gilks CB, McAlpine JN (2019) Molecular classification defines outcomes and opportunities in young women with endometrial carcinoma. Gynecologic oncology. doi:10.1016/j.ygyno.2019.03.098

14. Guo ZF, Guo WS, Xiao L, Gao GQ, Lan F, Lu XG, Li K, Liao DF (2012) Discrimination of A1555G and C1494T point mutations in the mitochondrial 12S rRNA gene by on/off switch. Applied biochemistry and biotechnology 166 (1):234-242. doi:10.1007/s12010-011-9419-4

15. Zhou C, Pu W, Yin YF, Xiao L, Luo D, Wang F, Peng C, Guo Z, Liu X, Xu H, Xing C, He N, Sun W, Cai W, Liao D, Li K (2018) A Novel Assay Coupling Dephosphorylation and Blue/White Colony Screening for the $\mathrm{G}>\mathrm{A}$ Hotspot Mutation at Codon 13 of KRAS Gene. Journal of nanoscience and nanotechnology 18 (1):538-543. doi:10.1166/jnn.2018.13935 


\section{Tables}

Table 1 Clinicopathological characteristics of patients with endometrial carcinoma

\begin{tabular}{|c|c|c|}
\hline observational index & number & ratio $\square 100 \% \square$ \\
\hline \multicolumn{3}{|l|}{ pathological pattern } \\
\hline adenocarcinomas & 52 & 83.9 \\
\hline Polypoid adenocarcinoma & 5 & 8.1 \\
\hline adenosquamous carcinoma & 3 & 4.8 \\
\hline clear cell carcinoma & 2 & 3.2 \\
\hline \multicolumn{3}{|l|}{ clinical stages } \\
\hline$\square$ & 50 & 80.6 \\
\hline II & 7 & 11.3 \\
\hline III & 5 & 8.1 \\
\hline \multicolumn{3}{|l|}{ histological grade } \\
\hline high differentiation $₫ \mathrm{G} 1 \square$ & 22 & 35.5 \\
\hline moderately differentiated $₫ \mathrm{G} 2 \square$ & 29 & 46.8 \\
\hline poorly differentiated $₫ \mathrm{G} 3 \square$ & 11 & 17.7 \\
\hline \multicolumn{3}{|l|}{ myometrial invasion } \\
\hline$\leq 1 / 2$ & 44 & 71.0 \\
\hline$>1 / 2$ & 18 & 29.0 \\
\hline
\end{tabular}

Table 2 Primer sequences for SNP detection

\begin{tabular}{llll}
\hline Mutation site & Sequence $\left(5^{\prime} \rightarrow 3^{\prime}\right)$ & & Size (bp) \\
& Wild forward & CCAGAGAAAAAGTCGGGAGATAAAG & \\
& primer(331F1) & & 347 \\
$+331 \mathrm{G} / \mathrm{A}$ & Mutation forward primer(331F2) & CCAGAGAAAAAGTCGGGAGATAAA $\underline{A}$ & \\
& Common reverse primer(331R) & AGGAGAAAGTGGGTGTTAATG TG & \\
\hline
\end{tabular}

Note: Bold and italic are sulphide modified bases; underlined are mutation bases. 
Table 3. Sequences of fluorescence quantitative PCR primers

\begin{tabular}{lll}
\hline Position & Sequence $\left(5^{\prime} \rightarrow 3^{\prime}\right)$ & Size $(\mathrm{bp})$ \\
\hline PRB-F & TCGGACACCTTGCCTGAAGT & 67 \\
PRB-R & CAGGGCCGAGGGAAGAGTAG & \\
PGR-F & GTGGGAGCTGTAAGGTCTTCTTTAA & 81 \\
PGR-R & AACGATGCAGTCATTTCTTCCA & \\
GAPDH-F & CAGGAGGCATTGCTGATGAT & 138 \\
GAPDH-R & GAAGGCTGGGGCTCATTT & \\
\hline
\end{tabular}

Table 4. The frequency of different genotypes of the PGR gene at $+331 \mathrm{G} / \mathrm{A}$

\begin{tabular}{|c|c|c|c|c|c|c|}
\hline \multirow[t]{2}{*}{ Groups } & \multicolumn{2}{|c|}{ Genotype frequency (\%) } & \multirow[t]{2}{*}{$P$} & \multicolumn{2}{|c|}{ Gene frequency (\%) } & \multirow[t]{2}{*}{$P$} \\
\hline & GG & $\mathrm{GA}+\mathrm{AA}$ & & $\mathrm{G}$ & A & \\
\hline Healthy control & $60(90.91)$ & $6(9.09)$ & 0.745 & $125(94.70)$ & $7(5.30)$ & 0.770 \\
\hline Endometrial cancer & $58(93.55)$ & $4(6.45)$ & & $119(95.97)$ & $5(4.03)$ & \\
\hline
\end{tabular}

Table 5. Differences in PRA and PRB mRNA expression and PRA/PRB between the two groups

\begin{tabular}{|c|c|c|c|c|c|}
\hline & \multicolumn{4}{|c|}{$2^{-\Delta \mathrm{Ct}}($ meanSD) } & \multirow{2}{*}{$2^{-\Delta \Delta C}$} \\
\hline & Control & Endometrial tissue sample & $\mathrm{t}$ & $P$ & \\
\hline PRB & 0.1440 .003 & 0.0570 .014 & -10.216 & $<0.0001$ & 0.396 \\
\hline PGR & 0.3300 .005 & 0.1010 .022 & -17.259 & $<0.0001$ & 0.306 \\
\hline PRA & 0.1860 .018 & 0.0440 .019 & -25.255 & $<0.0001$ & 0.237 \\
\hline PRA/PRB & 1.2970 .016 & 0.8550 .533 & -1.396 & 0.186 & 0.659 \\
\hline
\end{tabular}


Table 6. Assessment of the correlation between PRA and PRB expression and the PRA/PRB ratio between different genotypes

\begin{tabular}{|c|c|c|c|c|c|c|c|}
\hline & \multicolumn{5}{|c|}{$2^{-\Delta \mathrm{Ct}}($ meanSD) } & \multicolumn{2}{|c|}{$2^{-\Delta \Delta C t}$} \\
\hline & Control & GG & $\mathrm{GA}+\mathrm{AA}$ & $\mathrm{t}$ & $P$ & GG & $\mathrm{GA}+\mathrm{AA}$ \\
\hline PRB & 0.1440 .026 & 0.0600 .014 & 0.0470 .012 & 1.355 & 0.205 & 0.417 & 0.326 \\
\hline PGR & 0.3300 .046 & 0.0950 .022 & 0.1200 .099 & -1.923 & 0.083 & 0.288 & 0.364 \\
\hline PRA & 0.1860 .182 & 0.0350 .092 & 0.0730 .002 & -6.877 & $<0.0001$ & 0.188 & 0.392 \\
\hline PRA/PRB & 1.2970 .159 & 0.5950 .123 & 1.6360 .532 & -5.955 & $<0.0001$ & 0.459 & 1.261 \\
\hline
\end{tabular}

\section{Figures}

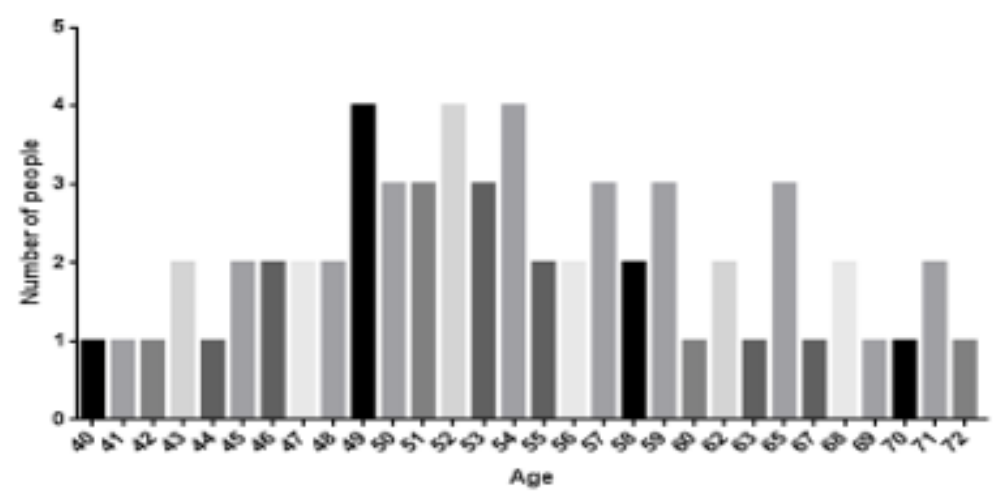

Figure 2

Age distribution of patients with endometrial cancer. The ages are shown for 62 patients with endometrial cancer who were admitted to the First Affiliated Hospital of the University of South China between May 2015 and July 2017.

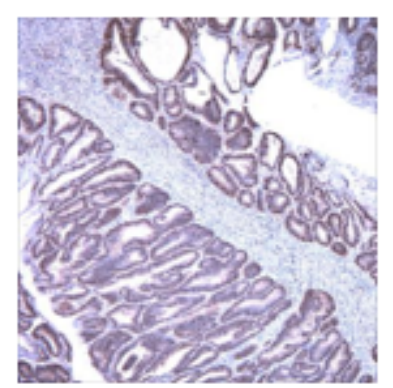

A

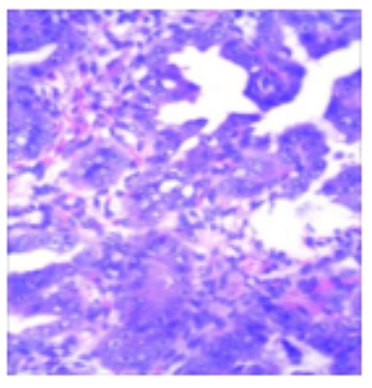

B

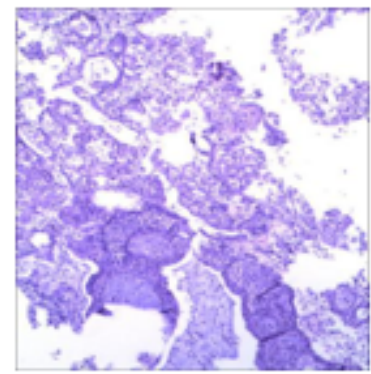

$\mathrm{C}$

Figure 4 
Histopathological diagnosis of partial histological sections. Representative sections are shown. (A) Adenocarcinoma of endometrium; (B) Endometrial clear-cell carcinoma; (C) Normal endometrium.

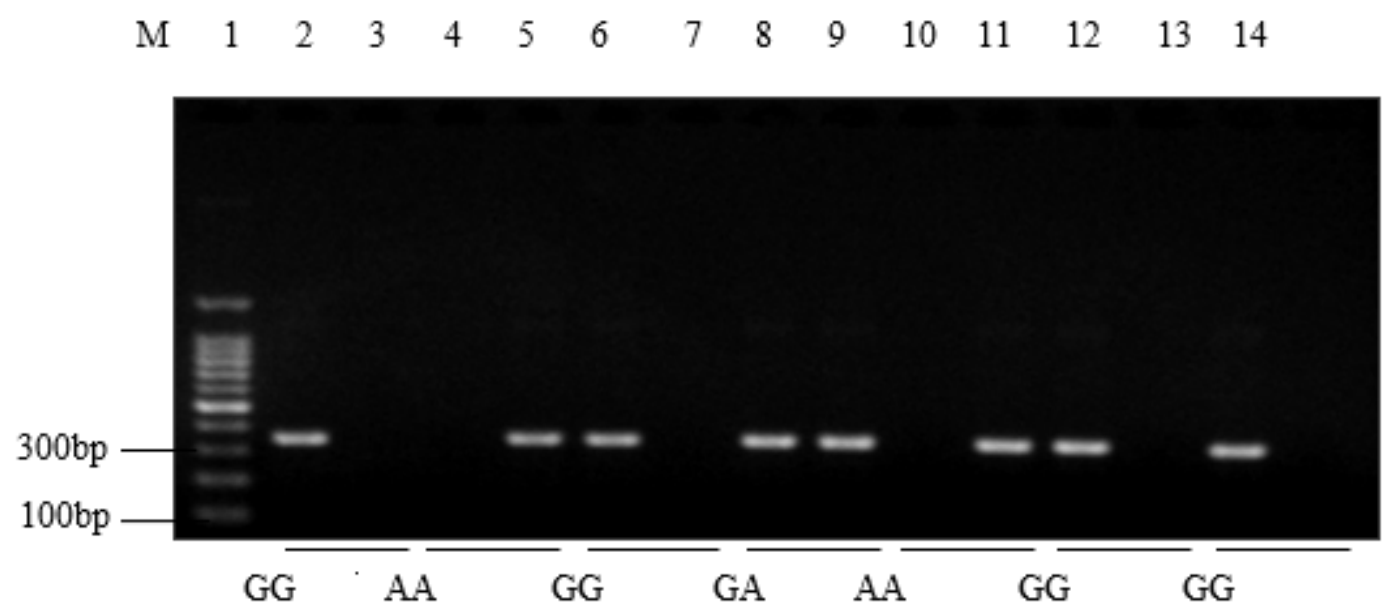

\section{Figure 6}

Discrimination of 331G/A mutations in the PGR gene using a mutation-sensitive on/off switch. $M$ is 100 bp DNA Ladder; Lanes 1 and 2 are wild-type control templates (GG); lanes 3 and 4 are mutant control templates (AA); Lanes 5 to 14 are different DNA samples; lanes 1, 3, 5, 7, 9, 11 and 13 are wild-type specific detection primers; lanes $2,4,6,8,10,12$ and 14 are mutant specific detection primers.

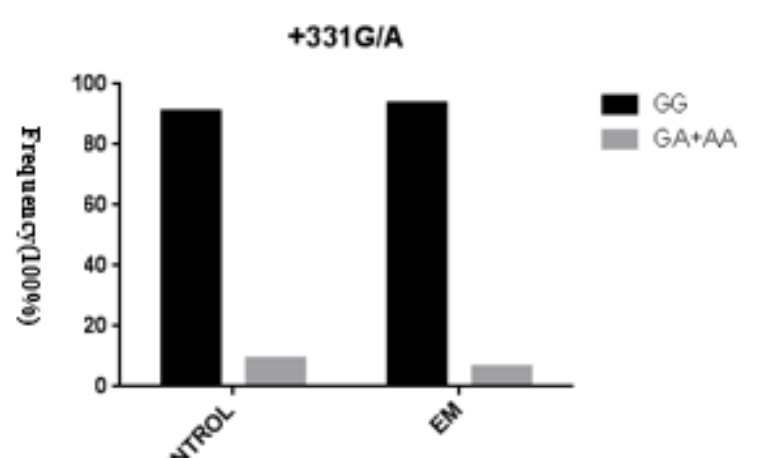

A

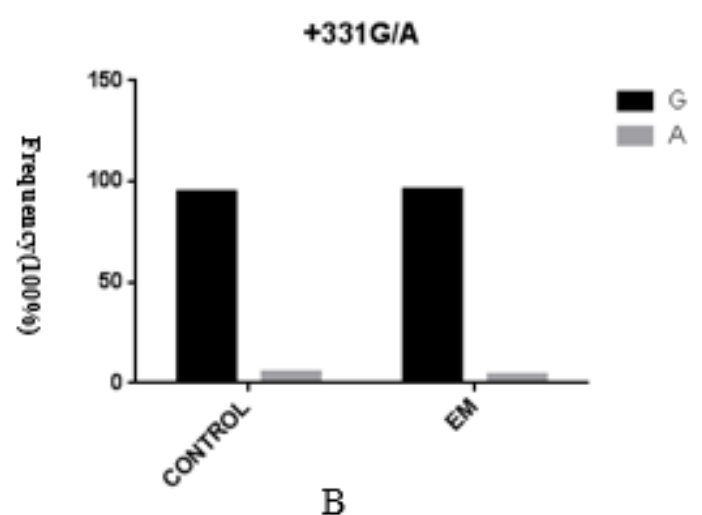

B

\section{Figure 8}

Genotype mapping of the PGR gene at +331G/A; $(A)+331 \mathrm{G} / \mathrm{A}$ genotype frequency of GG and GA+AA; $(B)$ $+331 \mathrm{G} / \mathrm{A}$ gene frequency of $\mathrm{G}$ and $\mathrm{A}$. The frequency was determined among 62 patients with endometrial cancer and 66 healthy controls. EM, endometrial cancer. 

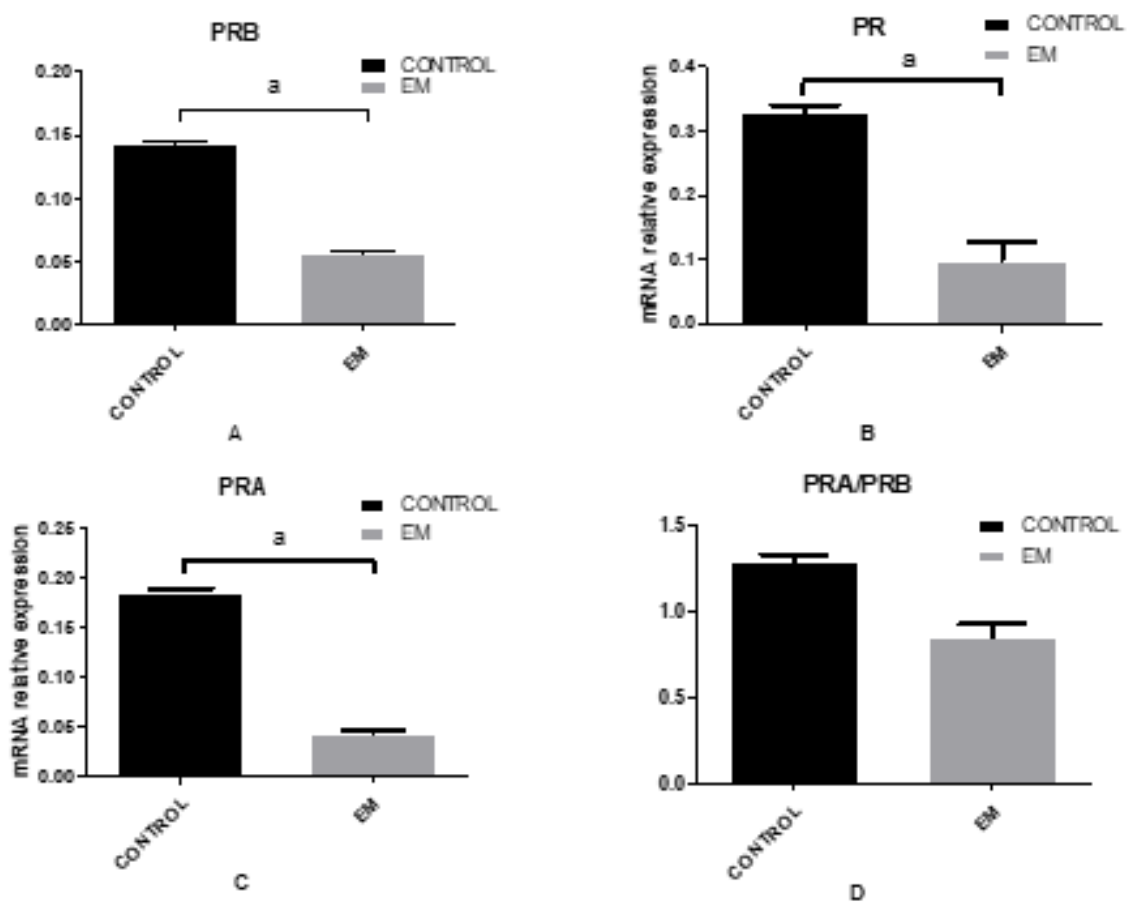

Figure 10

Comparison of PRB, PRG, and PRA mRNA expression and the ratio of PRA/PRB between the two groups of endometrial tissues. (A) The relative expression of PRB mRNA; (B) The relative expression of PR mRNA; (C) The relative expression of PRA mRNA; (D) The PRA/PRB ratio (a: $P<0.05)$. Values represent the average + S.D. of expression levels from 62 patients with endometrial cancer and 12 healthy controls. $\mathrm{EM}$, endometrial cancer.
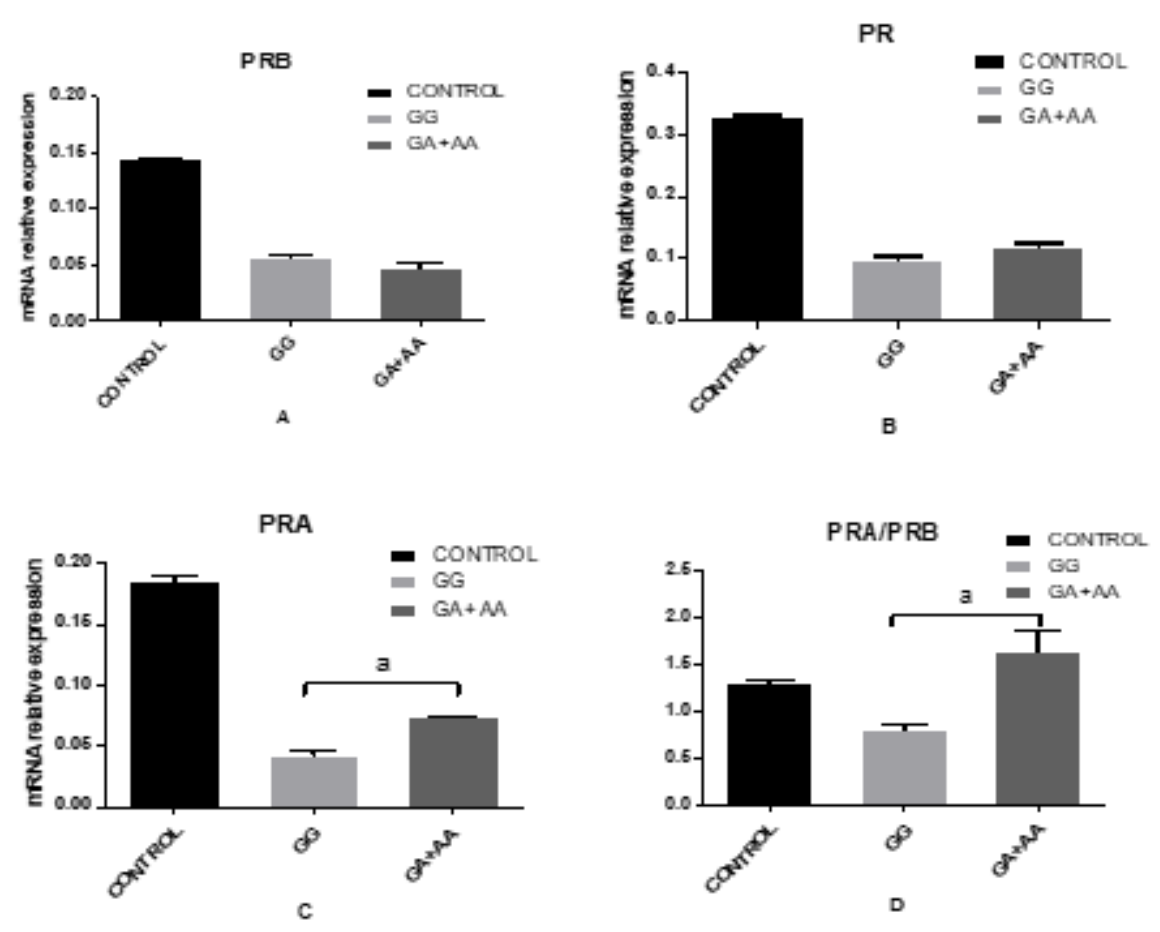
Figure 12

Comparison of PRB, PRG, and PRA mRNA expression and the ratio of PRA/PRB between endometrial cancer patients with differing genotypes. (A) The relative expression of PRB mRNA; (B) The relative expression of PR mRNA; (C) The relative expression of PRA mRNA; (D) PRA/PRB (a: $P<0.05)$ Values represent the average + S.D. of expression levels from 62 patients with endometrial cancer (?\# with the GG genotype and ?\# with the GA+AA genotype) and 12 healthy controls. EM, endometrial cancer.

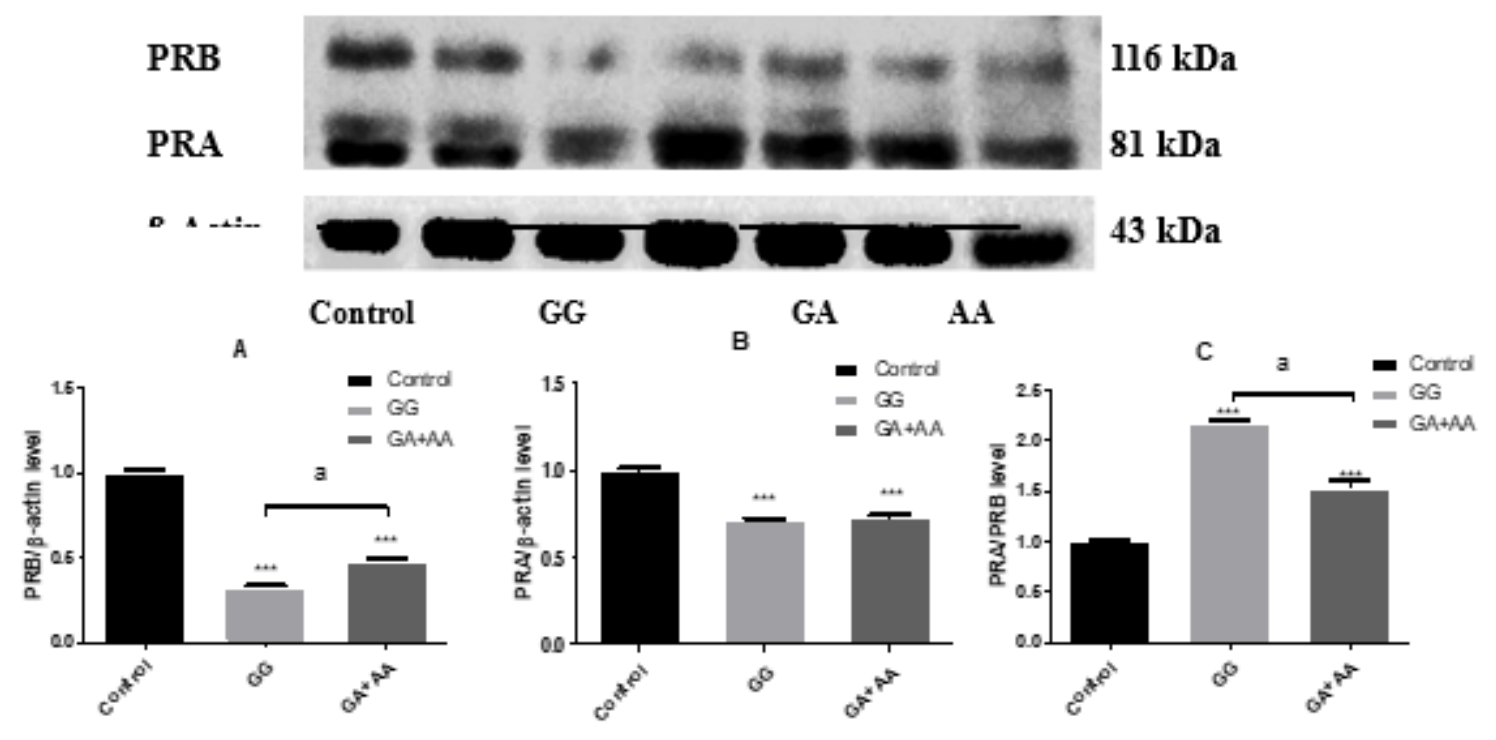

Figure 14

The differences in PR, PRA, and PRB protein expression and the ratio of PRA/PRB between different genotypes. (A) Representative Western blot showing the protein expression of healthy controls and patients with endometrial cancer of each genotype. (B) The protein expression level of PRB. (C) The protein expression level of PRA (D) The ratio of PRA/PRB ( $n$ is the number of samples in each group, a: $P<0.05$, comparison among groups; ${ }^{\star \star *} P<0.0001$ vs. control). Representative of the results from ?\# samples of each group. 